\title{
Correlation between the antioxidant capacity of plasma and blood glucose level
}

\author{
Eva Nurinda ${ }^{1}$, Emelda$^{2}$, Nurul Kusumawardani ${ }^{3}$ \\ ${ }^{1}$ Department of Pharmacology, Alma Ata University, Bantul, Yogyakarta, Indonesia \\ ${ }^{2}$ Department of Herbal Pharmacy, Alma Ata University, Bantul, Yogyakarta, Indonesia \\ ${ }^{3}$ Department of ClinicalPharmacy, Alma Ata University, Bantul, Yogyakarta, Indonesia
}

Keywords
Antioxidants
Blood glucose
Diabetes mellitus
Total antioxidant capacity
Correspondence
Eva Nurinda
Department of Pharmacology
Alma Ata University
Brawijaya Road no.99 Jadan
Tamantirto
Bantul
Yogyakarta 55183
Indonesia
evanurinda@gmail.com

Keywords

Antioxidants

Blood glucose

Diabetes mellitus

Correspondence

Eva Nurinda

Alma Ata University

Brawijaya Road no.99 Jadan

Tamantirto

Yogyakarta 55183

evanurinda@gmail.com

\section{Introduction}

Diabetes mellitus can be caused by oxidative stress and oxidative damage in tissues. These can also cause other diseases such as atherosclerosis or rheumatoid arthritis. Patients with type 2 diabetes mellitus often have various tissues affected by oxidative stress, including pancreatic $\beta$ cells (Tangvarasittichai, 2015).

Glucose can be oxidized before binding to proteins, as glycated proteins can be oxidized to produce reactive oxygen species (ROS) (Tiganis, 2011). Hyperglycemia exacerbates the formation of ROS by several mechanisms. ROS increase the expression and formation of tumour necrosis factor- $\alpha$ (TNF- $\alpha$ ) and exacerbate oxidative stress. TNF- $\alpha$ can cause insulin resistance in many ways, such as by decreasing the autophosphorylation of insulin receptors, changing the substrate for insulin receptor 1 to inhibit insulin receptor tyrosine kinase activity, decreasing the sensitivity of glucose insulin transporter (GLUT-4), increasing the circulation of fatty acids, changing its function, $B$ cells and increasing triglyceride levels and by decreasing HDL levels. Previous studies have shown that TNF- $\alpha$ injection in healthy test animals will reduce insulin sensitivity due to hyperglycemia without decreasing plasma insulin levels (Dewanjee et al., 2018).

Antioxidants can decrease free radical levels as proved by Luo and the authors (2019), and thereby reducing insulin resistance (Luo et al., 2019). Antioxidants can decrease reactive oxygen species (ROS), which as a result reduces oxygen which will bind to free electrons released due to the electron chain leak. The reaction 
between oxygen and free electrons produces ROS in mitochondria (Annisa et al., 2014).

Secondary metabolites found in plants can act as antioxidants; an example of these are flavonoids. Flavonoids derived from vegetables and medicinal plants have beneficial effects on diabetes by improving glycemic control, lipid profile, and antioxidant status. The antioxidants in flavonoids can donate their hydrogen atoms. Flavonoids will be oxidized and bind to free radicals so that the free radicals become more stable compounds (Ghorbani, 2017).

Several studies have been conducted on Indonesian herbs that are used for anti-diabetes in order to study their antioxidant activity. Most of these studies were conducted in vitro, such as a study conducted by Rui Wang, in which he examined the composition of volatile compounds in five species of cinnamon. In his research, it was known that the cinnamon antioxidant activity was $45.42 \%$ by using the DPPH method (Wang et al., 2009). Cinnamon twig bark has the highest antioxidant activity compared to bark and branches assayed semiquantitatively by using the DPPH method (Ervina et al., 2016). The standardized extract of Curcuma xanthorrhiza and the active component Xanthorrizol significantly weakened the induction of a high-fat diet (HFD) against hyperglycemia and insulin resistance (Kim et al., 2014). Puranik conducted a study looking at the antidiabetic activity of Tinospora cordifolia. According to his study, Tinospora cordifolia had significant antidiabetic activity in diabetic rats by $40 \%$ to $80 \%$ compared to insulin (Puranik et al., 2010). Another plant that has antidiabetic potential is Averrhoa bilimbi $L$ because its leaves contain flavonoids. Flavonoids function as antioxidants and antidiabetics (Alhassan \& Ahmed, 2016). In previous studies that examined flavonoids in several Indonesian plants, researchers wanted to evaluate the pharmacological decrease in blood glucose levels by using herb extract. Its relationship with the total antioxidant capacity of the blood was studied and compared with glibenclamide which is widely used in diabetic treatment.

\section{Materials and methods}

\section{Extract preparation}

The extractions of Cinnamomum zeylanicum, Tinuspora Cordifolia, Curcuma xanthorrhiza and Averrhoa blimbi L. were carried out by soaking the samples in $70 \%$ ethanol in a ratio of 1:10 for 24 hours while stirring for the first two hours. Remaceration was also carried out once so that the active substance in the Simplicia could be optimally extracted.

\section{Preparation of the test animals}

As shown in Figure 1, 42 white male rats (Rattus norvegicus) aged seven to eight weeks were used. They weighed 179.29 grams on average and were divided into seven groups (six in rats in each group). The groups included $\mathrm{K} 1=$ normal rats, $\mathrm{K} 2=$ hyperglycemic rats (induced by streptozotocin (STZ) + nicotinamide), K3 = hyperglycemic rats (induced by STZ + nicotinamide) + glibenclamide, $\mathrm{K} 4$ = hyperglycemic rats (induced by STZ + nicotinamide) + ethanolic Extract of Tinuspora Cordifolia, $\mathrm{K} 5$ = hyperglycemic rats (induced by STZ + nicotinamide) + ethanolic extract of Averrhoa blimbi $L$, $\mathrm{K} 6=$ hyperglycemic rats (induced by $\mathrm{STZ}+$ nicotinamide) + ethanolic extract of Cinnamomum zeylanicum, $\mathrm{K} 7$ = hyperglycemic rats (induced by STZ + nicotinamide) + ethanolic extract of Curcuma xanthorrhiza.

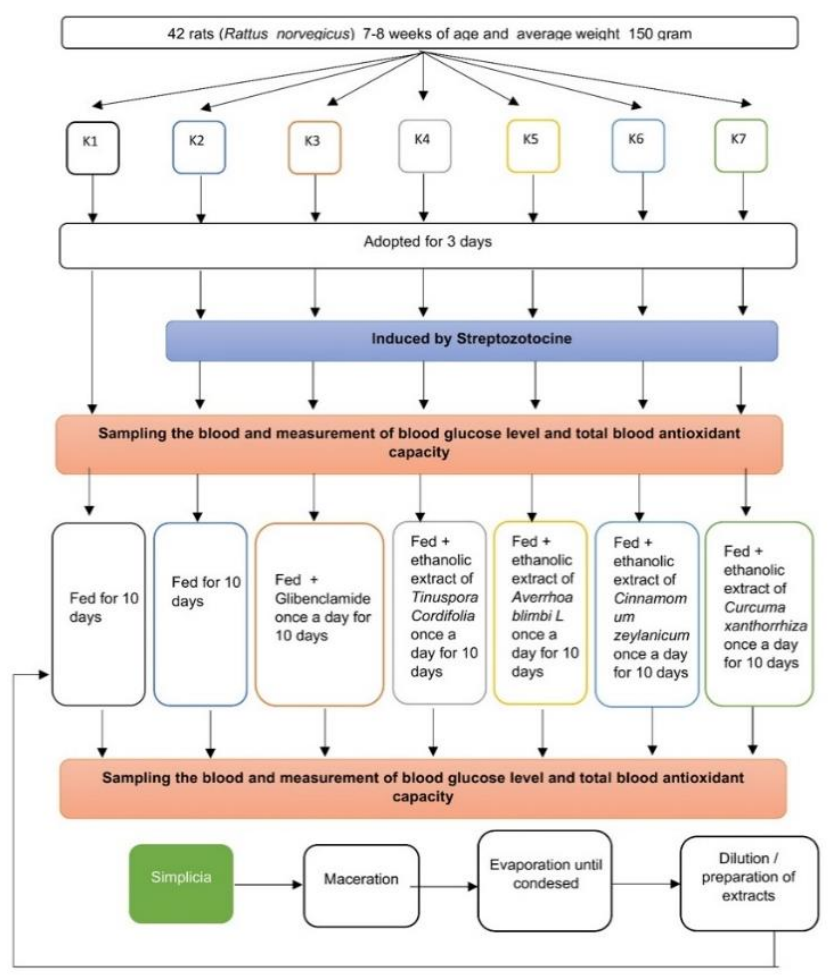

Figure 1: Experiment flow chart

\section{Testing and experimental design}

Firstly, all rats were conditioned to the laboratory conditions for three days. Then, the $\mathrm{K} 2-\mathrm{K} 7$ groups were given $45 \mathrm{mg}$ of STZ per kg of body weight in order to make them hyperglycemic. Their blood glucose level was measured before and after STZ induction. Following this, the $\mathrm{K} 3$ group was given $0.09 \mathrm{mg}$ of glibenclamide per $200 \mathrm{~g}$ of body weight, K4 was given $90 \mathrm{mg}$ of ethanolic extract of Tinuspora Cordifolia per $200 \mathrm{~g}$, K5 was given $15 \mathrm{mg}$ of ethanolic extract of 
Averrhoa blimbi L per $200 \mathrm{~g}$ of body weight, K6 was given $50 \mathrm{mg}$ of ethanolic extract of Cinnamomum zeylanicum per $200 \mathrm{~g}$ of body weight, $\mathrm{K} 7$ was given 30 mg ethanolic extract of Curcuma xanthorrhiza orally per $200 \mathrm{~g}$ of body weight. At the end of the observation (day 11), the blood glucose level and total antioxidant capacity of plasma were measured.

\section{Analysis}

Reduction of the blood glucose level was calculated by subtracting the blood glucose level after ten days of the treatment from the blood glucose level before treatment. The same formula was also applied to measure the total antioxidant capacity of plasma. The mean differences of the blood glucose level and the total antioxidant capacity of plasma were analysed statistically using the One Way Anova test and LSD post hoc test with $\alpha=0.05$ with SPSS statistic 25 . The correlation between the total antioxidant capacity of plasma with the reduction of blood glucose level was analysed statistically by using regression in which reduction of blood glucose level acted as a dependent variable.

\section{Result}

\section{Total antioxidant capacity of plasma before and after treatment}

Figure 2 indicates that there was a significant difference between the mean antioxidant capacity of plasma between hyperglycemic rats that did not receive treatment and those that received ethanolic extract treatment. $\mathrm{K} 1$ and $\mathrm{K} 2$ were not treated with compounds that act as antioxidants. The antioxidant capacity improved in the group of rats that were treated with compounds for ten days, while the normal and hyperglycemic rats experienced a reduction (Figure 2). This meant that there was a decrease in free radical levels due to the ethanolic extract. The mean improvement of the total antioxidant capacity was different in the $\mathrm{K} 3, \mathrm{~K} 4, \mathrm{~K} 5$, and $\mathrm{K} 6$ groups, but the total antioxidant capacity value after treatment could be twice from the baseline (before treatment) or more, and it was observed to be statistically significant $(p<0,05)$ using paired sample t-test pre and posttreatment (as shown in Table I). The comparative compound used was glibenclamide which is widely used to treat type 2 diabetes mellitus, and it was proved to successfully increase the antioxidant capacity of plasma. It indicated that the ethanolic extract of Cinnamomum zeylanicum was the strongest compound. It could increase the total antioxidant capacity of plasma better than Tinuspora Cordifolia, Averrhoa blimbi L or Curcuma xanthorrhiza.

The statistical analysis (Table I) revealed that the total antioxidant capacity of plasma between the K3 and K6 groups or between the $\mathrm{K} 4$ and $\mathrm{K} 7$ groups was not significantly different $(p<0.05)$. This meant that the ethanolic extracts of Cinnamomum zeylanicum had the same antioxidant capacity as that of glibenclamide. Meanwhile, the ethanolic extracts of Tinospora cordifolia had the same antioxidant capacity as that of Curcuma xanthorrhiza.

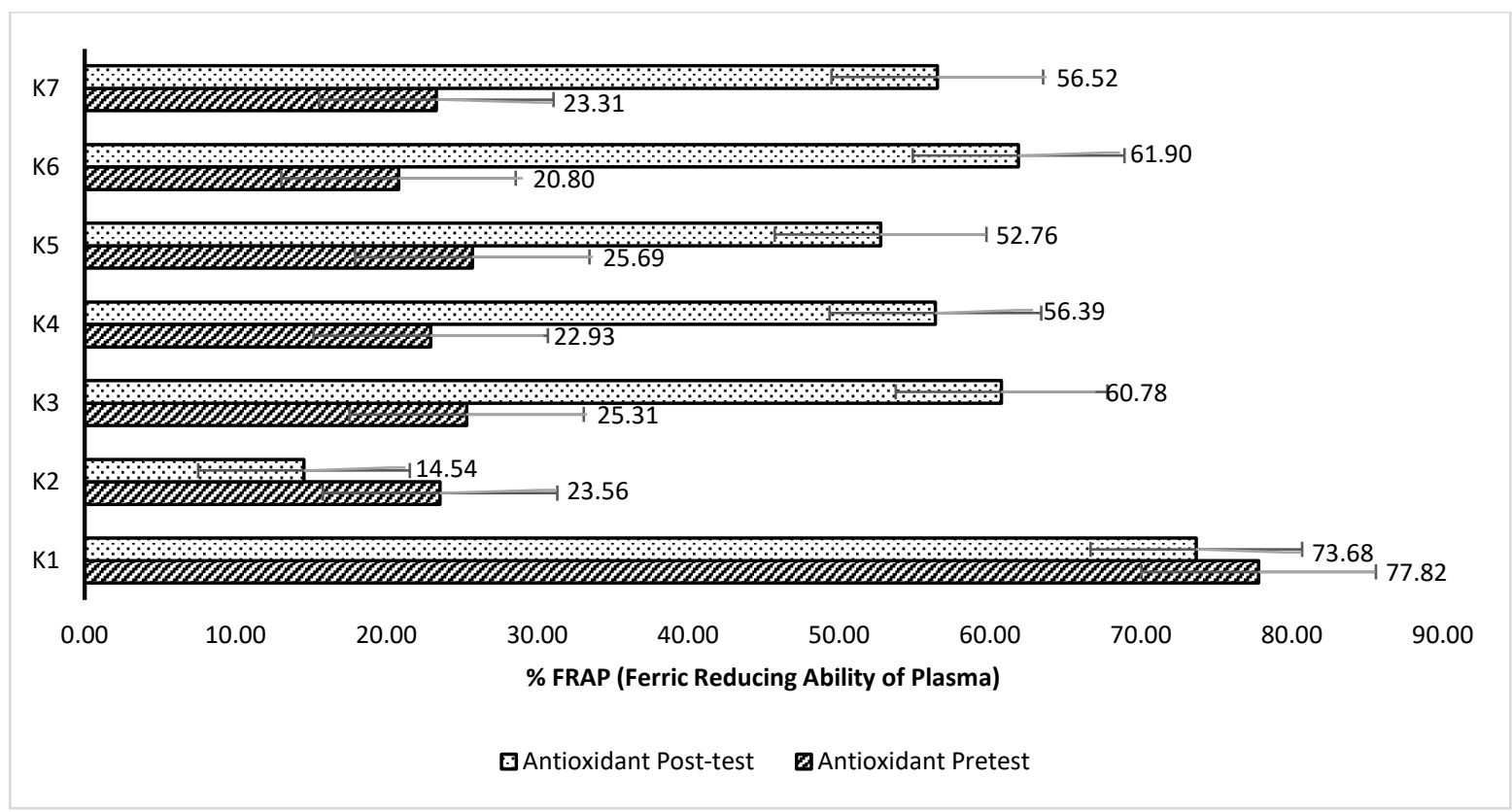

Figure 2: Total antioxidant capacity of plasma 
Table I: Mean of the increase of the total antioxidant capacity of plasma and the reduction of blood glucose level

\begin{tabular}{|c|c|c|c|c|}
\hline \multirow{3}{*}{ Group } & \multirow{2}{*}{\multicolumn{2}{|c|}{$\begin{array}{l}\text { Increase of the total antioxidant capacity of plasma } \\
\text { (\% FRAP) }\end{array}$}} & \multicolumn{2}{|c|}{ Reduction of blood glucose level (mg/dL) } \\
\hline & & & & \\
\hline & Mean & $\pm S D$ & Mean & $\pm S D$ \\
\hline K1 & -4.14 & 2.22 & $-2.91^{\mathrm{a}}$ & 1.77 \\
\hline K2 & -9.02 & 4.82 & $-4.56^{a}$ & 3.67 \\
\hline K3 & $40.10^{\mathrm{a}}$ & 4.42 & $124.58^{b}$ & 7.05 \\
\hline K4 & $33.46^{\mathrm{a}}$ & 2.46 & $117.68^{c}$ & 6.70 \\
\hline K5 & 27.07 & 3.52 & 108.68 & 7.69 \\
\hline K6 & 41.10 & 4.19 & $130.90^{b}$ & 3.43 \\
\hline K7 & $33.21^{\mathrm{a}}$ & 2.91 & $123.01^{c}$ & 9.09 \\
\hline
\end{tabular}

$\mathrm{K} 1=$ normal rats

$\mathrm{K} 2$ = Hyperglycemic rats (induced by STZ + nicotinamide)

$\mathrm{K} 3=$ Hyperglycemic rats (induced by STZ + nicotinamide) + Glibenclamide

K4 = Hyperglycemic rats (induced by STZ + nicotinamide) + Ethanolic Extract of Tinuspora Cordifolia

$\mathrm{K} 5$ = Hyperglycemic rats (induced by STZ + nicotinamide) + Ethanolic Extract of Averrhoa blimbi L

K6 $=$ Hyperglycemic rats (induced by STZ + nicotinamide) + Ethanolic Extract of Cinnamomum zeylanicum

K7 = Hyperglycemic rats (induced by STZ + nicotinamide) + Ethanolic Extract of Curcuma xanthorrhiza

The same superscript letter showed that there were no differences between the groups (LSD post hoc ANOVA with $p$-value $>0,05$ )

\section{Blood glucose level before and after treatment}

Figure 3 shows that the mean of the baseline blood glucose level (before STZ injection) in every group is placed on the same line. This means that the animals were healthy and homogenous, so they were able to be randomly separated into groups. After STZ injection, blood glucose levels in K2-K7 groups increased significantly and was placed at the same level. This meant that STZ successfully made the rats hyperglycemic and gave them type 2 Diabetes mellitus. Figure 3 also reveals that using ethanolic extract in treatment can decrease blood glucose levels significantly, although it has yet to be as effective as glibenclamide. It shows that ethanolic extract of Cinnamomum zeylanicum is the strongest compound at decreasing blood glucose levels compared to ethanolic extract of Tinuspora Cordifolia, Averrhoa blimbi $L$ or Curcuma xanthorrhiza.

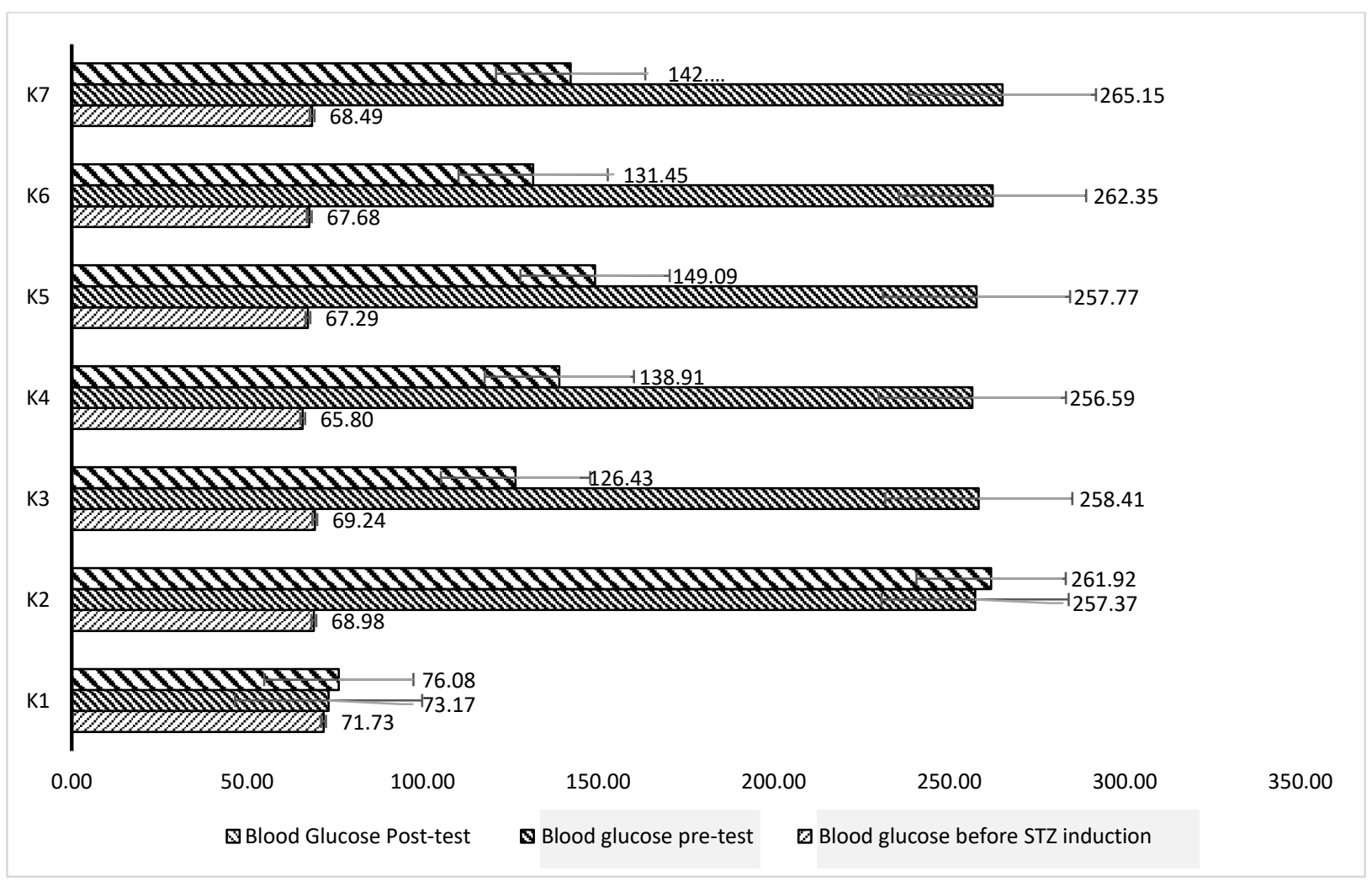

Figure 3: Blood glucose level before and after treatment 
The correlation between the total antioxidant capacity of plasma and blood glucose level

The results of this study indicate that Tinospora cordifolia and Curcuma zanthorrhiza have equivalent potential to reduce blood glucose levels as glibenclamide, thereby increasing superoxide dismutase (SOD) activity and total antioxidant capacity in diabetic rats. This was approved by a linear relationship between the total antioxidant capacity of plasma and the glucose levels, which was inversely proportional to $96,67 \%$. This states that there was a perfect negative linear relationship between the posttest mean of total antioxidant capacity variation and the mean of plasma glucose levels. The equation of this correlation, as shown in Figure 4, was $y=0,3211 x-$ 5,4386 . This means that for every $1 \mathrm{mg} / \mathrm{L}$ of total antioxidant capacity of plasma $(x)$ that is added, the glucose in the blood will decrease by $0.326 \mathrm{mg} / \mathrm{dL}$.

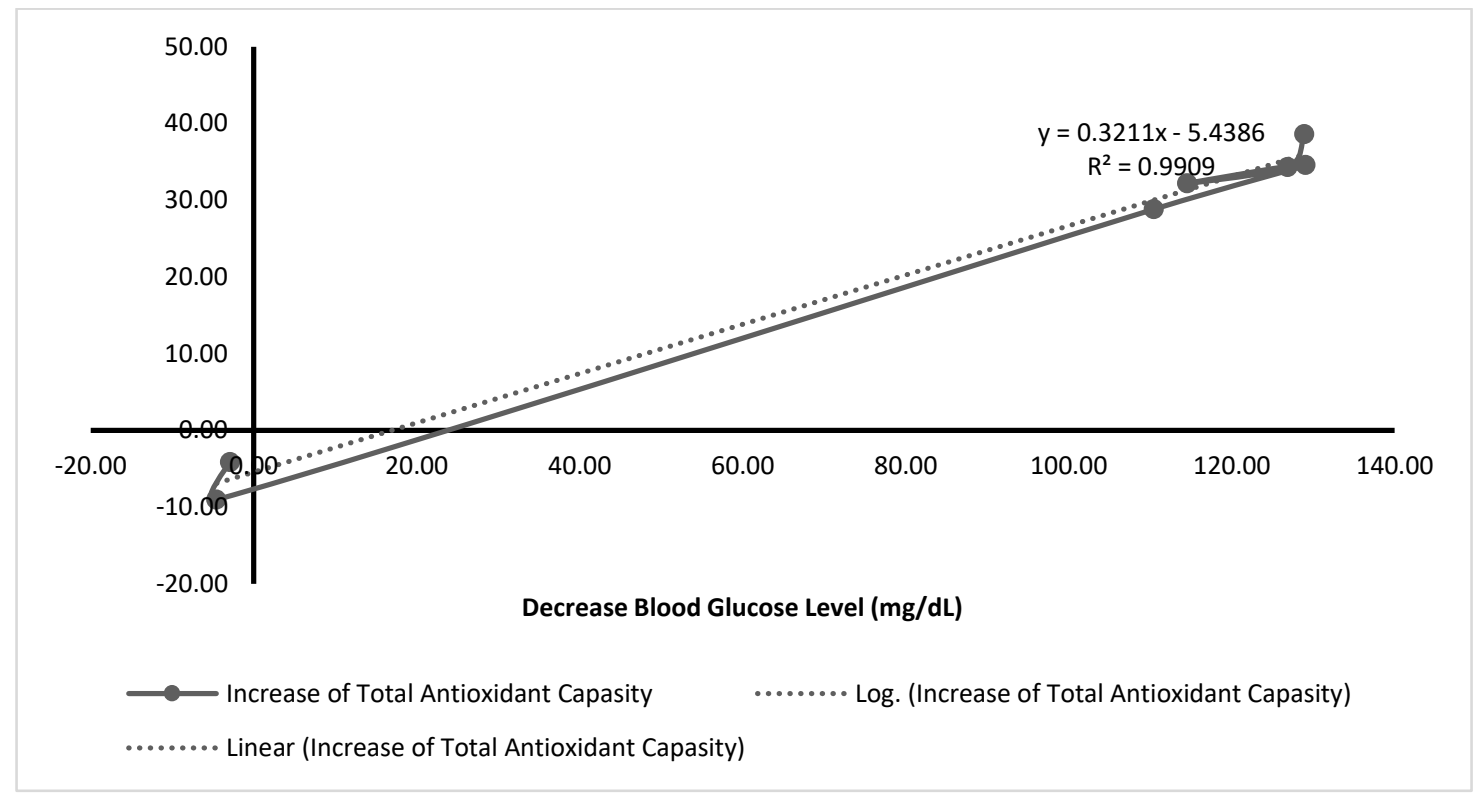

Note: equation is $y=0.3211 x-5.4386$ where $y=$ blood glucose level, and $x=$ antioxidant capacity of plasma

Figure 4: The correlation between total antioxidant capacity of plasma and blood glucose level

\section{Discussion}

\section{Total antioxidant capacity of plasma was increased by treatment}

Antioxidant potential was measured using the frap method. The principle of the frap method is based on the ability of the sample to transfer electrons to reduce the iron ion $\mathrm{Fe}^{3+}$ (ferro) to iron ion $\mathrm{Fe}^{2+}$ (ferri). Antioxidant capacity is one of the parameters that shows how much potential a substance has to act as an antioxidant (Pisoschi \& Negulescu, 2012). The greater the total antioxidant capacity of plasma, the greater the ability of these compounds to act as antioxidants.

The total antioxidant capacity of the ethanolic extract from Tinospora cordifolia, Cinnamomum zeylanicum, and Curcuma xanthorrhiza is associated with the chemical compounds in these plants, which possess antioxidant activity. Polysaccharide compounds in the form of arabinogalactan, galacturonic acid, and neutral glucan found in Cinnamomum zeylanicum are known to act as antioxidants (Ghosh et al., 2015). Cinnamomum zeylanicum contains volatile oil with the main components being eugenol, cinnamaldehyde, and camphor which act as antioxidants, antimicrobials, and antidiabetic (Jayaprakasha \& Rao, 2011). Cinnamomum zeylanicum bark and fruits contain proanthocyanidins which are flavonoids. In the ethanolic extract of Tinospora cordifolia, there are main components such as tinocordioside, cordifolide A, palmatine, quercetin, 8 sitosterol, heptacosanol, and syringin (Kumar et al., 2018). One of the compounds that act as an antioxidant in Tinospora cordifolia is flavonoid quercetin. Quercetin is a 3-hydroxyl group flavonoid that neutralizes free radicals by one-step hydrogen atom or electron transfer followed by proton transfer during which they are oxidized (Lesjak et al., 2018). The essential oils contained in this plant are able to capture strong free radicals with DPPH with a total phenolic content of 28 $\pm 0.4 \mathrm{mg} \mathrm{GAE} / \mathrm{g}$ (Naik et al., 2014).

The ability of free radical scavenging in Curcuma xanthorhiza is associated with chemical compounds contained in this plant, including curcumin, demethoxycurcumin, and bisdemethoxycurcumin, which have strong antioxidant activity (Jantan et al., 
2012). Curcumin is the compound with the strongest antioxidant ability compared to demetoxycurcumin and bisdemetethoxycurcumin (Jayaprakasha et al., 2006).

\section{Blood glucose level decreased by the treatment}

Rats that were given STZ-induced DM had similar pathophysiology as type 2 DM patients. STZ 2-Deoxy-2[[(methylnitrosoamino)carbonyl]amino $]-D$ -

glucopyranose is a cytotoxic glucose analogue, and its cytotoxicity is derived from the ßcell selective action mechanisms (Islam et al., 2017). STZ is selectively accumulated in pancreatic $\beta$ cells via the low-affinity GLUT2 glucose transporter in the plasma membrane (Gauthier, 2014; Jayasimha Goud \& Swamy, 2015). The effects of STZ on glucose and insulin homeostasis reflect the toxin-induced abnormalities in $\beta$ cell function. Initially, insulin biosynthesis, glucose-induced insulin secretion and glucose metabolism (both glucose oxidation and oxygen consumption) are all affected (Nagarchi et al., 2015; Wu \& Yan, 2015). At later stages of functional $\beta$ cell impairment, gene expression and protein production deficiencies lead to the deterioration of both glucose transport and metabolism ( Khaki et al., 2014; Kumar M, 2017).

The results revealed that all of the extracts made blood glucose levels decrease, and the best performance was obtained when Cinnamomum zeylanicum extract was used. The mean reduction of blood glucose level gained by using ethanolic extract in Cinnamomum zeylanicum is statistically significantly similar to the mean reduction obtained by using glibenclamide. Other experts reported that cinnamon extract plays a role in regulating blood glucose levels and lipids. It may also exert a blood glucose-suppressing effect by improving insulin sensitivity or slowing the absorption of carbohydrates in the small intestine (Abd et al., 2010; Sartorius et al., 2014).

Phytochemical screening on cinnamon bark Simplicia indicates that the Simplicia contains secondary metabolite compounds, namely tannins, phenolics, flavonoids, quinones, saponins, monoterpenes, and sesquiterpenes (Adisakwattana et al., 2011; Assefa et al., 2018). Flavonoids stimulate glucose uptake in peripheral tissues, regulate the activity and/or express the rate-limiting enzymes in the carbohydrate metabolism canal, and act as insulin secretagogues or insulin mimetics, possibly influencing the pleiotropic mechanisms of insulin signalling to ameliorate the diabetes condition (Cazarolli et al., 2008; Testa et al., 2016).
There is a correlation between the escalation of total antioxidant capacity of plasma and the decline of blood glucose level

Diabetes mellitus is characterised by hyperglycemia and average haemoglobin A1c levels (HbA1c) above $48 \mathrm{mmol} / \mathrm{mol}(6.5 \%)$ for two to three months (JeanMarie, 2018). This is caused by vascular dysfunction due to repeated exposure and pathologically high $\mathrm{d}$ glucose concentrations (Domingueti et al., 2016). The occurrence of vascular dysfunction is caused by disruption of the nitric oxide (NO) canal and an increase in oxidative stress, which will cause changes in glucose metabolism (Ghasemi \& Jeddi, 2017). The results show that the proactive phytochemical exploration of Tinospora cordifolia and Curcuma zanthorrhiza in this study was obtained by antioxidant compounds from the measurement of the total antioxidant capacity, which is important for reducing glucose in the blood in Streptozotocin-induced DM rats. If hyperglycemia is not controlled in a Diabetes mellitus patient, it will cause further oxidative stress because hyperglycemia in diabetes mellitus leads to the excessive production of free radicals. This is characterised by an increase in malondialdehyde (MDA), peroxidation index, and a decrease in antioxidant protection in the body (Domingueti et al., 2016; Fouelifack et al., 2019).

The content of antioxidant compounds is determined by the presence of free $-\mathrm{OH}$ (hydroxyl) functional groups and carbon-carbon double bonds, such as flavones, flavanones, squalene, tocopherol $\beta$-carotene and vitamin C (Babu et al., 2013). These bioactive compounds support the linear relationship between the decrease in blood glucose and the total antioxidant capacity so that they can prevent further vascular dysfunction in Diabetes mellitus (Hussain et al., 2020). The total antioxidant activity from the results of this study illustrates the antioxidant status of STZ-induced rat blood samples, and it proves that the antioxidant response to free radicals is produced due to hyperglycemic conditions. Antioxidant activity describes the ability of an antioxidant compound to neutralise free radicals so that it can delay, slow down, and prevent the occurrence of free radical antioxidation reactions in lipid oxidation (Shahidi \& Zhong, 2015). The mechanism of reducing blood glucose levels is carried out by stimulating the secretion of the insulin hormone, increasing glucose uptake from blood to tissues, oxidating glucose, and activating glycogen synthesis in the liver and adipose tissue (Lee \& Jun, 2014; Bhatt et al., 2016). Increased cumulative action of all the antioxidants present in plasma and body fluids in vivo will be able to balance oxidants and antioxidants. As a result, oxidative stress will decrease, and this will be marked by a decrease in glucose in the 
blood (Birben et al., 2012; Jamuna Rani \& Mythili, 2014; Pruchniak et al., 2016).

\section{References}

Abd, S. N., Rahman, E., Abdel-Haleem, A. M. H., \& Al Mudhaffar, H. M. (2010). Antidiabetic effect of cinnAmon powder And cinnAmon Aqueous extrAct on serum glucose of rAts. International Journal of Food, Nutrition and Public Health.

Adisakwattana, S., Lerdsuwankij, O., Poputtachai, U., Minipun, A., \& Suparpprom, C. (2011). Inhibitory Activity of Cinnamon Bark Species and their Combination Effect with Acarbose against Intestinal $\alpha$-glucosidase and Pancreatic $\alpha$-amylase. Plant Foods for Human Nutrition. https://doi.org/10.1007/s11130-011-0226-4

Alhassan, A., \& Ahmed, Q. (2016). Averrhoa bilimbi Linn.: A review of its ethnomedicinal uses, phytochemistry, and pharmacology. In Journal of Pharmacy and Bioallied Sciences. https://doi.org/10.4103/0975-7406.199342

Annisa, F., Viryawan, C., \& Santoso, F. (2014). Hipoksia Berpeluang Mencegah Kerusakan Sel $\beta$ Pankreas pada Pasien Diabetes Melitus Tipe 2: Tinjauan Biologi Molekuler. $C d k$

Assefa, A. D., Keum, Y. S., \& Saini, R. K. (2018). A comprehensive study of polyphenols contents and antioxidant potential of 39 widely used spices and food condiments. Journal of Food Measurement and Characterization. https://doi.org/10.1007/s11694-018-9770-z

Babu, P. V. A., Liu, D., \& Gilbert, E. R. (2013). Recent advances in understanding the antidiabetic actions of dietary flavonoids. In Journal of Nutritional Biochemistry. https://doi.org/10.1016/j.jnutbio.2013.06.003

Bhatt, H., Saklani, S., \& Upadhayay, K. (2016). Antioxidant and antidiabetic activities of ethanolic extract of Primula Denticulata Flowers. Indonesian Journal of Pharmacy. https://doi.org/10.14499/indonesianjpharm27iss2pp74

Birben, E., Sahiner, U. M., Sackesen, C., Erzurum, S., \& Kalayci, O. (2012). Oxidative stress and antioxidant defense. In World Allergy Organization Journal. https://doi.org/10.1097/WOX.0b013e3182439613

Cazarolli, L., Zanatta, L., Alberton, E., Reis Bonorino Figueiredo, M., Folador, P., Damazio, R., Pizzolatti, M., \& Mena Barreto Silva, F. (2008). Flavonoids: Cellular and Molecular Mechanism of Action in Glucose Homeostasis. Mini-Reviews in Medicinal Chemistry. https://doi.org/10.2174/138955708785740580

Dewanjee, S., Das, S., Das, A. K., Bhattacharjee, N., Dihingia, A., Dua, T. K., Kalita, J., \& Manna, P. (2018). Molecular mechanism of diabetic neuropathy and its pharmacotherapeutic targets. In European Journal of Pharmacology. https://doi.org/10.1016/j.ejphar.2018.06.034

Domingueti, C. P., Dusse, L. M. S. A., Carvalho, M. D. G., De Sousa, L. P., Gomes, K. B., \& Fernandes, A. P. (2016). Diabetes mellitus: The linkage between oxidative stress, inflammation, hypercoagulability and vascular complications. In Journal of Diabetes and its Complications. https://doi.org/10.1016/j.jdiacomp.2015.12.018

Ervina, M., Nawu, Y. E., \& Esar, S. Y. (2016). Comparison of in vitro antioxidant activity of infusion, extract and fractions of Indonesian Cinnamon (Cinnamomum burmannii) bark. International Food Research Journal
Fouelifack, F. Y., Sama, J. D., \& Sone, C. E. (2019). Assessment of adherence to iron supplementation among pregnant women in the yaounde gynaeco-obstetric and paediatric hospital. Pan African Medical Journal. https://doi.org/10.11604/pamj.2019.34.211.16446

Gauthier, E. L. (2014). Streptozotocin: Uses, mechanism of action and side effects. In Streptozotocin: Uses, Mechanism of Action and Side Effects

Ghasemi, A., \& Jeddi, S. (2017). Anti-obesity and antidiabetic effects of nitrate and nitrite. In Nitric Oxide - Biology and Chemistry. https://doi.org/10.1016/j.niox.2017.08.003

Ghorbani, A. (2017). Mechanisms of antidiabetic effects of flavonoid rutin. In Biomedicine and Pharmacotherapy. https://doi.org/10.1016/j.biopha.2017.10.001

Ghosh, T., Basu, A., Adhikari, D., Roy, D., \& Pal, A. K. (2015). Antioxidant activity and structural features of Cinnamomum zeylanicum. 3 Biotech, 5(6), 939-947. https://doi.org/10.1007/s13205-015-0296-3

Hussain, T., Tan, B., Murtaza, G., Liu, G., Rahu, N., Saleem Kalhoro, M., Hussain Kalhoro, D., Adebowale, T. O., Usman Mazhar, M., Rehman, Z. ur, Martínez, Y., Akber Khan, S., \& Yin, Y. (2020). Flavonoids and type 2 diabetes: Evidence of efficacy in clinical and animal studies and delivery strategies to enhance their therapeutic efficacy. In Pharmacological Research. https://doi.org/10.1016/j.phrs.2020.104629

Islam, M., Rupeshkumar, M., \& Reddy, K. B. (2017). Streptozotocin is more convenient than Alloxan for the induction of Type 2 diabetes. International Journal of Pharmacological Research

Jamuna Rani, A., \& Mythili, S. V. (2014). Study on total antioxidant status in relation to oxidative stress in type 2 diabetes mellitus. Journal of Clinical and Diagnostic Research. https://doi.org/10.7860/JCDR/2014/7603.4121

Jantan, I., Saputri, F. C., Qaisar, M. N., \& Buang, F. (2012). Correlation between chemical composition of curcuma domestica and curcuma xanthorrhiza and their antioxidant effect on human low-density lipoprotein oxidation. EvidenceBased Complementary and Alternative Medicine, 2012. https://doi.org/10.1155/2012/438356

Jayaprakasha, G. K., Ohnishi-Kameyama, M., Ono, H., Yoshida, M., \& Rao, L. J. (2006). Phenolic constituents in the fruits of Cinnamomum zeylanicum and their antioxidant activity. Journal of Agricultural and Food Chemistry, 54(5), 1672-1679. https://doi.org/10.1021/jf052736r

Jayaprakasha, G. K., \& Rao, L. J. M. (2011). Chemistry, biogenesis, and biological activities of cinnamomum zeylanicum. Critical Reviews in Food Science and Nutrition, 51(6), 547-562. https://doi.org/10.1080/10408391003699550

Jayasimha Goud, B., \& swamy, Bkc. (2015). Streptozotocin -A Diabetogenic Agent in Animal Models www.ijppr.humanjournals.com. Human Journals Review Article April

Jean-Marie, E. (2018). Diagnosis and classification of diabetes mellitus. In Encyclopedia of Endocrine Diseases. https://doi.org/10.1016/B9780-12-801238-3.65822-1

Khaki, A., Khaki, A. A., Hajhosseini, L., Golzar, F. S., \& Ainehchi, N. (2014). The antioxidant effects of ginger and cinnamon on spermatogenesis dys-function of diabetes rats. African 
Journal of Traditional, Complementary and Alternative Medicines. https://doi.org/10.4314/ajtcam.v11i4.1

Kim, M. B., Kim, C., Song, Y., \& Hwang, J. K. (2014). Antihyperglycemic and anti-inflammatory effects of standardized Curcuma xanthorrhiza Roxb. Extract and its active compound xanthorrhizol in high-fat diet-induced obese mice. Evidence-Based Complementary and Alternative Medicine. https://doi.org/10.1155/2014/205915

Kumar M, S. (2017). Optimization of Yield for Extraction of an Essential Oil from Cinnamon Using Microwave-Assisted Extraction. Journal of Chromatography \& Separation Techniques. https://doi.org/10.4172/2157-7064.s8-001

Kumar, V., Singh, S., Singh, A., Dixit, A. K., Srivastava, B., Sidhu, G. K., Singh, R., Meena, A. K., Singh, R. P., Subhose, V., \& Prakash, O. (2018). Phytochemical, Antioxidant, Antimicrobial, and Protein Binding Qualities of Hydroethanolic Extract of Tinospora cordifolia. Journal of Biologically Active Products from Nature, 8(3), 192-200. https://doi.org/10.1080/22311866.2018.1485513

Lee, Y. S., \& Jun, H. S. (2014). Antidiabetic actions of glucagon-like peptide-1 on pancreatic beta-cells. In Metabolism: Clinical and Experimental. https://doi.org/10.1016/j.metabol.2013.09.010

Lesjak, M., Beara, I., Simin, N., Pintać, D., Majkić, T., Bekvalac, K., Orčić, D., \& Mimica-Dukić, N. (2018). Antioxidant and anti-inflammatory activities of quercetin and its derivatives. Journal of Functional Foods, 40, 68-75. https://doi.org/10.1016/j.jff.2017.10.047

Luo, Y., Peng, B., Wei, W., Tian, X., \& Wu, Z. (2019). Antioxidant and antidiabetic activities of polysaccharides from guava leaves. Molecules. https://doi.org/10.3390/molecules24071343

Nagarchi, K., Ahmed, S., Sabus, A., \& Saheb, S. H. (2015). Effect of Streptozotocin on glucose levels in albino wister rats. Journal of Pharmaceutical Sciences and Research

Naik, D., Dandge, C., \& Rupanar, S. (2014). Determination of Chemical Composition and Evaluation of Antioxidant Activity of Essential Oil from Tinospora cordifolia (Willd.) Leaf. Journal of Essential Oil-Bearing Plants, 17(2), 228-236. https://doi.org/10.1080/0972060X.2013.831568

Pisoschi, A. M., \& Negulescu, G. P. (2012). Methods for Total Antioxidant Activity Determination: A Review. Biochemistry \& Analytical Biochemistry. https://doi.org/10.4172/21611009.1000106

Pruchniak, M. P., Araźna, M., \& Demkc, U. (2016). Biochemistry of oxidative stress. In Advances in Experimental Medicine and Biology. https://doi.org/10.1007/5584_2015_161

Puranik, N., Kammar, K. F., \& Devi, S. (2010). Antidiabetic activity of tinospora cordifolia (Willd.) in streptozotocin diabetic rats; does it act like sulfonylureas? Turkish Journal of Medical Sciences. https://doi.org/10.3906/sag-0802-40

Sartorius, T., Peter, A., Schulz, N., Drescher, A., Bergheim, I., MacHann, J., Schick, F., Siegel-Axel, D., Schürmann, A., Weigert, C., Häring, H. U., \& Hennige, A. M. (2014). Cinnamon extract improves insulin sensitivity in the brain and lowers liver fat in mouse models of obesity. PLOS ONE. https://doi.org/10.1371/journal.pone.0092358

Shahidi, F., \& Zhong, Y. (2015). Measurement of antioxidant activity. In Journal of Functional Foods. https://doi.org/10.1016/j.jff.2015.01.047
Tangvarasittichai, S. (2015). Oxidative stress, insulin resistance, dyslipidemia and type 2 diabetes mellitus. World Journal of Diabetes. https://doi.org/10.4239/wjd.v6.i3.456

Testa, R., Bonfigli, A. R., Genovese, S., De Nigris, V., \& Ceriello, A. (2016). The possible role of flavonoids in the prevention of diabetic complications. In Nutrients. https://doi.org/10.3390/nu8050310

Tiganis, T. (2011). Reactive oxygen species and insulin resistance: The good, the bad and the ugly. In Trends in Pharmacological Sciences. https://doi.org/10.1016/j.tips.2010.11.006

Wang, R., Wang, R., \& Yang, B. (2009). Extraction of essential oils from five cinnamon leaves and identification of their volatile compound compositions. Innovative Food Science and Emerging Technologies. https://doi.org/10.1016/j.ifset.2008.12.002

Wu, J., \& Yan, L. J. (2015). Streptozotocin-induced type 1 diabetes in rodents as a model for studying mitochondrial mechanisms of diabetic $\beta$ cell glucotoxicity. In Diabetes, Metabolic Syndrome and Obesity: Targets and Therapy. https://doi.org/10.2147/DMSO.S82272 